\title{
Os desafios bioéticos da interrupção voluntária de hidratação e nutrição em fim de vida no ordenamento jurídico brasileiro*
}

\author{
Luciana Dadalto $\cdot$ Sarah Carvalhob
}

Resumo: O presente artigo, por meio de pesquisa teórica de natureza exploratória, aborda como o direito de morrer é tratado no ordenamento jurídico brasileiro; assim, destaca suas principais nomenclaturas, a saber: distanásia, ortotanásia, cuidados paliativos, diretivas antecipadas de vontade e morte medicamente assistida. Destarte, o objetivo principal é tratar da interrupção voluntária de comer e beber, como possibilidade de antecipar a morte e, por conseguinte, discutir se é um meio viável ou não para se alcançar uma morte digna. Ressalta-se que o procedimento não está previsto de forma explícita nas normas brasileiras e inexistem pesquisas sobre a sua legitimidade no ordenamento pátrio como meio de se alcançar a morte digna, razão pela qual o presente artigo se justifica.

Palavras-chave: autonomia; bioética; fim de vida; interrupção voluntária de comer e beber; morte digna

Recibido: 01/09/2020

Aceptado: 27/07/2021

Disponible en línea: 31/12/2021.

* Este artigo é fruto de pesquisa realizada pelo Grupo de Estudos e Pesquisas em Bioética do Centro Universitário Newton Paiva, Belo Horizonte, Brasil.

a Doutora em Ciências da Saúde pela Faculdade de Medicina da Universidade Federal de Minas Gerais, Brasil. Mestre em Direito Privado pela Pontifícia Universidade Católica de Minas Gerais, Brasil. Professora da Escola de Direito do Centro Universitário Newton Paiva, Belo Horizonte, Brasil. Correio eletrônico: luciana@lucianadadalto.com.br ORCID: https://orcid.org/0000-0001-5449-6855

b Advogada. Pós-graduanda em Ciências Criminais e Interseccionalidade. Bacharela em Direito pelo Centro Universitário Newton Paiva, Belo Horizonte, Brasil.

Correio eletrônico: advocacia.sarahcarvalho@gmail.com ORCID: http://orcid.org/0000-0002-9665-5559 
Cómo citar: Dadalto L, Carvalho S. Os desafios bioéticos da interrupção voluntária de hidratação e nutrição em fim de vida no ordenamento jurídico brasileiro. Rev. latinoam. bioet [Internet]. $31^{\circ}$ de dezembro de 2021 [citado $31^{\circ}$ de dezembro de 2021];21(2):127-142. Disponível em: https://revistas.unimilitar.edu.co/index.php/rlbi/article/view/5181

\title{
The Bioethical Challenges of the End-of-Life Voluntary Interruption of Hydration and Nutrition in the Brazilian Legal System
}

\begin{abstract}
Through theoretical research of an exploratory nature, this article addresses how the right to die is treated in the Brazilian legal system; thus, it highlights its main nomenclatures: dysthanasia, orthothanasia, palliative care, advance directives of will, and medically assisted death. The primary purpose is to deal with the voluntary interruption of eating and drinking as a possibility to hasten death and, therefore, discuss whether it is a viable means to have a dignified death. We emphasize that the procedure is not explicitly provided for in the Brazilian regulations and that there are no studies into its legitimacy as a means to achieve a dignified death in the national system, which justifies this article.
\end{abstract}

Keywords: Autonomy; bioethics; end of life; voluntary interruption of eating and drinking; dignified death

\section{Los retos bioéticos de la interrupción voluntaria de hidratación y nutrición en el final de vida en el ordenamiento jurídico brasileño}

Resumen: El presente artículo, mediante investigación teórica de naturaleza exploratoria, aborda cómo el derecho de morir es tratado en el ordenamiento jurídico brasileño; así, destaca sus principales nomenclaturas: distanasia, ortotanasia, cuidados paliativos, directivas anticipadas de voluntad y muerte médicamente asistida. De este modo, el propósito principal es ocuparse de la interrupción voluntaria de comer y beber, como posibilidad de adelantar la muerte y, por ende, discutir si es un medio viable o no para lograr una muerte digna. Se resalta que el procedimiento no está previsto de forma explícita en las normas brasileñas y no existen investigaciones sobre su legitimidad en el ordenamiento patrio como medio de alcanzar la muerte digna, por lo cual el artículo se justifica.

Palabras clave: autonomía; bioética; final de la vida; interrupción voluntaria de comer y beber; muerte digna 


\section{Introdução}

A bioética, na perspectiva acadêmica, ascendeu em 1970, em um período em que os movimentos em prol dos direitos dos pacientes emergiram ante os dilemas éticos oriundos do desenvolvimento tecnológico. Surge, então, a teoria principialista, cunhada pelos bioeticistas americanos Beauchamp e Childress em 1979, a fim de orientar os conflitos morais por meio de quatro princípios básicos universais: a autonomia, a beneficência, a não maleficência e a justiça.

Entre esses princípios, destaca-se a autonomia, que trata da governança sobre as próprias ações e pressupõe a relação consigo mesmo, mas também com os outros. Em razão disso, os projetos atinentes à pessoalidade do indivíduo não podem se sobrepor aos projetos da coletividade e devem estar alinhados à dignidade da pessoa humana.

Desde a promulgação da Constituição da República Federativa do Brasil de 1988, os princípios da liberdade, da dignidade, do pluralismo e a busca pela construção da pessoalidade humana, através da liberdade individual, passaram a ser base do ordenamento jurídico. Assim, no contexto democrático brasileiro, todos podem ter uma visão própria do que significa viver dignamente, e a compreensão de que a morte coloca fim a essa pessoalidade permite resguardar também a existência de uma autonomia para morrer.

Nessa perspectiva, ao se falar de liberdades individuais e de seu exercício, sobretudo no que tange ao processo de morrer, tem-se que o ordenamento jurídico brasileiro permite a defesa da morte digna como direito fundamental de forma ampla, contudo se verifica, na prática, que certos valores constitucionais são restringidos de forma a tolher projetos de vidas plurais.

\section{Dignidade no morrer}

Atul Gawande (1) afirma que o avanço médico científico foi o responsável por adiar a morte e, por conseguinte, dificultou que profissionais da saúde, pautados pelo paradigma da cura, compreendam as vontades do paciente e respeitem-nas. Contudo, o autor deixa claro que até que a morte chegue
- vez que não é possível afastá-la indefinidamente -, os cuidados médicos são fundamentais para aferir se o percurso final será gradual ou brusco.

Atualmente, em virtude de todo o aparato tecnológico, é possível que haja a manutenção da vida por um período indefinido e tal possibilidade fez surgir uma cultura que tornou o paciente refém dessa aparelhagem, em detrimento da disponibilização de opções autônomas, a fim de que ele próprio decida como quer ser tratado em situação de terminalidade de vida (2).

Sobre isso, tem-se que uma pesquisa realizada em 2017 pela Kaiser Foundation (3), cujo objetivo foi abordar a experiência do Brasil, do Japão, dos Estados Unidos e da Itália acerca dos cuidados em fim de vida, aferiu que o país em que mais se valoriza o prolongamento artificial da vida em prejuízo do alívio da dor é o Brasil. Esse fenômeno é denominado "distanásia”, tendo como sinônimo as expressões "futilidade terapêutica", "obstinação terapêutica", "tratamentos extraordinários".

Drane (4, p. 94) esclarece que

futilidade não equivale a ineficácia provada. É um termo contextualmente específico. O que é útil em um contexto pode não ser em outras circunstâncias. Um tratamento fútil não apresenta benefícios ao paciente e se chega a essa conclusão tendo por parâmetro a situação do paciente, quero dizer, a gravidade da doença, a esperança de vida, a qualidade de vida do paciente, seus interesses e seus projetos.

De acordo com a Associação Médica Americana, não há um conceito único para o referido termo, tendo em vista a sua relação com os objetivos do paciente e com os seus valores (5). Em um primeiro momento, compreende-se que a distanásia, etimologicamente, é resultado da junção do prefixo dis (separação, disjunção, negação) com que se refere a thanatos ou morte (6). Brito e Rijo (7) já elucidaram que se trata do prolongamento da vida biológica para além de seu período natural e não da vida digna em si, já que, por vezes, a vida biográfica do paciente sequer existe mais.

Nessa perspectiva, Beauchamp e Childress (8) elucidam que o tratamento poderá ser considerado como fútil quando não proporcionar benefícios reais ao paciente, uma vez que a morte é inevitável. 
Trata-se, assim, de uma definição genérica e subjetiva, cujo julgamento depende mais precisamente dos valores do paciente do que da técnica, razão pela qual é preciso se atentar às particularidades de cada caso específico para ser possível aferir se está diante de um tratamento extraordinário (9).

A pesquisa realizada pela Kaiser Family Foundation (3), em que aponta a preferência brasileira pelos tratamentos extraordinários, é contrária ao conceito atual do que significa morte digna no Brasil. A distanásia é prática corriqueira nos consultórios e nos hospitais médicos brasileiros e, entre os possíveis motivos, estão a ilusão de que a disponibilidade dos recursos terapêuticos existe para resolver todo e qualquer sofrimento, para dar mais tempo para que o milagre aconteça, além da dificuldade em se aceitar a finitude da vida, tendo a morte como um inimigo a ser combatido (6).

A aceitação da terminalidade da vida como fato natural é o arcabouço dos cuidados paliativos. Durante certo tempo, entendeu-se que tais cuidados eram considerados como tratamento ordinário, classificação atribuída pela Igreja Católica por meio de sua teologia moral, que distinguia tratamento extraordinário e ordinário de modo a diferenciar o tratamento obrigatório daquele que não deveria ser utilizado, respectivamente (10).

Essa distinção contribuiu com o preconceito em torno da nomenclatura cuidados paliativos e por isso há quem defenda atualmente a substituição do termo por cuidados integrais, cuidados de suporte ou suporte avançado, tendo em vista que o cuidado não pode ser considerado como prêmio de consolação quando a cura não é obtida; ao contrário, deve ser parte integral do projeto de tratamento do paciente (11). Sobre isso, Leo Pessini pontua: "diante da vulnerabilidade provocada pela doença, exige-se uma resposta: o cuidado." (12, p. 195)

Nesse sentido, é sabido que a história dos cuidados paliativos data de tempos antigos, vez que, em muitas culturas, havia lugares em que os peregrinos, os doentes e os necessitados podiam buscar abrigo e cuidados. Esses ambientes eram chamados "hospices" e durante a Idade Média, na Europa, tornaram-se o lugar para os cuidados aos doentes e às pessoas em situação de terminalidade (13, p. 168 , grifos do original):
À medida que a prática da medicina foi se desenvolvendo ao longo dos séculos, e o hospital se tornou um lugar central em que os médicos podiam praticar sua ciência de curar, os pacientes na fase final tornaram-se um símbolo de "impotência" no prolongamento da vida, e dessa forma a medicina evidenciou suas limitações ao não desenvolver respostas apropriadas às necessidades daquelas pessoas. Os hospices, onde existiam, continuaram a prover apoio e cuidados espirituais, mas a ideia de cuidado especializado dos pacientes terminais tornou-se realidade nos anos 1950 quando Dame Cicely Saunders, que fundou o St. Christopher Hospice, em Londres, descreveu a filosofia do cuidado da pessoa que está morrendo, que desde então conhecemos como cuidados paliativos.

Por definição da Organização Mundial de Saúde, os cuidados paliativos se configuram como (14, p. 92):

abordagem de melhora a qualidade de vida dos pacientes (adultos ou crianças) e de seus familiares que enfrentam problemas associados a doenças que ameacem a vida. Previne e alivia o sofrimento por meio da investigação precoce, avaliação correta e tratamento da dor e de outros problemas físicos, psicossociais ou espirituais.

Esse conceito foi ampliado pela International Association for Hospice e Palliative Care em 2019, com o intuito de incluir o cuidado holístico ativo de indivíduos em todas as idades, que tenham sofrimentos ocasionados por doenças graves, sobretudo aqueles que estejam em estado de terminalidade de vida, objetivando a qualidade de vida não apenas dos pacientes, mas também dos cuidadores e da família (15).

Os cuidados paliativos, portanto, visam diminuir o sofrimento do paciente sem possibilidades terapêuticas de cura por meio de abordagem interdisciplinar, valendo-se de propostas farmacológicas avançadas a fim de controlar sintomas, combinando ciência e humanismo (16). Paulina Taboada menciona cinco princípios que devem orientar os cuidados paliativos, a saber: o princípio da veracidade, o da proporcionalidade terapêutica, o do duplo efeito, o da prevenção e o do não abandono (17).

O princípio da veracidade é aquele que fundamenta a confiança nas relações interpessoais, o que 
implica dizer que a comunicação acerca da verdade ao paciente possibilita sua participação ativa no processo de tomada de decisões autônomas (18). Já o princípio da proporcionalidade enuncia que há "uma obrigação moral de se implementar todas aquelas medidas terapêuticas que tenham uma relação de proporção entre os meios empregados e o resultado previsível" $(12$, p. 195).

O princípio do duplo efeito aclara que um mesmo ato pode ser bom e ruim ao mesmo tempo ao paciente e que a sua licitude está condicionada ao cumprimento de requisitos (17), enquanto o princípio da prevenção trata de prever as possíveis complicações e/ou sintomas que possam se apresentar ao longo do cuidado, a fim de implementar medidas para evitá-las. Por fim, há o princípio do não abandono, máxima que diz que mesmo não sendo possível curar, ainda há o que ser feito, cuidar e ser solidário (12).

É importante dizer que o movimento hospice, que originou os cuidados paliativos, é contemporâneo ao testamento vital, um documento escrito por uma pessoa no pleno gozo de suas faculdades mentais, cujo objetivo é dispor sobre os cuidados, os tratamentos e os procedimentos a que deseja ou não ser submetida quando for acometido por uma doença ameaçadora da vida, fora de possibilidades terapêuticas e impossibilitado de manifestar livremente sua vontade (18). O testamento vital é um dos produtos de um movimento mundial em prol do reconhecimento dos direitos dos pacientes, surgido no pós-Segunda Guerra Mundial.

É sabido que o testamento vital precisa ter conteúdo lícito no país em que se efetiva; dessa forma, no que tange à possibilidade de o paciente ter explicitado seu desejo de ser submetido a procedimentos considerados como típicos da distanásia em seu testamento vital, tem-se que, no Brasil, a disposição deve ser interpretada como não escrita por ser considerada como prática contrária às normas ético-disciplinares (18).

Assim, se porventura esse desejo for manifestado diante dos profissionais de saúde, orienta-se que se esclareça ao paciente sobre a sua impossibilidade e, persistindo a manifestação, que seja solicitada a autorização ao comitê de ética da instituição ou do Conselho Regional de Medicina a fim de tratar do conflito em questão, tendo em vista que a situação poderá ocasionar conflitos entre os familiares e a equipe médica (18).

Além disso, considerando a autodeterminação do paciente e sabendo que não é possível obrigar o médico a incorrer em infração ética, será viável discutir a possibilidade de o paciente ter seu desejo atendido caso arque com seus cuidados de saúde e encontre um profissional que esteja disposto a realizar uma prática contrária às normas éticas de sua profissão.

Por sua vez, a ortotanásia, método que privilegia a autonomia do paciente e assegura os cuidados paliativos, é uma nomenclatura advinda dos radicais gregos orthos, que significa correto, e thanatos, que significa morte, ou seja, a morte que não é adiada tampouco antecipada (19).

A respeito disso, Leo Pessini descreve que o "compromisso com a promoção do bem-estar do doente crônico e terminal permite-nos não somente falar de saúde, mas também desenvolver o conceito de ortotanásia, a arte de bem morrer" (12, p. 92, grifos do original). Dessa forma, é possível conceituá-la como a abstenção ou a limitação da futilidade terapêutica diante da morte iminente do paciente, preservando assim os cuidados básicos com sua saúde (20).

Verifica-se que muitos autores brasileiros fazem a diferenciação entre a ortotanásia e a eutanásia passiva, de modo a dizer que a primeira se trata da suspensão de tratamento que perdeu a sua indicação por ser visto como inútil ao indivíduo, enquanto a segunda se trata da suspensão de medidas úteis que seriam indicadas àquele caso específico, com o intuito de antecipar a morte (21).

Entretanto, convém esclarecer que a "eutanásia passiva" é uma expressão utilizada como sinônimo de "ortotanásia" nas línguas anglo-saxãs, uma vez que, em tais idiomas, não existe o neologismo "ortotanásia" razão pela qual se entende que a diferenciação ora trazida está ultrapassada (18).

A ortotanásia deve ser vista como uma prática terapêutica capaz de garantir a dignidade do paciente em situação de terminalidade, contudo é preciso esclarecer que, no que tange às disposições de recusa e/ou aceitação de cuidados e tratamentos, não se pode considerar no ordenamento jurídico 
brasileiro que a recusa aos cuidados paliativos seja um pedido ilícito. O conceito de tratamento digno é subjetivo e, portanto, impor a ortotanásia como um conceito fixo de morte digna é fazer com que o paternalismo médico perdure (18).

Em verdade, é possível assumir que, antes dos avanços tecnológicos, a ortotanásia era o comum, pois a sociedade compreendia a morte como um fato natural, vez que não havia meios de prolongar artificialmente a vida.

As discussões sobre a abreviação da vida, por sua vez, remontam aos tempos mais remotos da humanidade e, juntamente com a ortotanásia e a distanásia, fazem parte das questões afetas ao chamado "direito de morrer" ou de viver a própria morte.

O questionamento integra o rol das situações jurídicas existencialistas (22), haja vista que a expressão "morte digna" pressupõe que o sujeito possa decidir como deseja morrer, caso se depare com uma doença ameaçadora de vida. Afirmar isso, porém, não se configura como legitimar o desejo pela morte; ao contrário, visa preservar o direito constitucional de exercício da autonomia em um momento inerente a toda vida: a terminalidade.

Diante disso, ganham destaque os meios para se alcançar a morte digna, emergindo conceitos já explicados como distanásia, ortotanásia, além de outros como a mistanásia e a morte medicamente assistida. Ao se falar em dignidade da pessoa humana, tem-se em mente o seu caráter polissêmico e dotado de diferentes significados de valores éticos. Seu conceito pode ser utilizado para defender, inclusive, vontades antagônicas (12).

O direito à vida é considerado um direito universal por estar positivado no artigo $3^{\circ}$ da Declaração Universal dos Direitos Humanos de 1948, além de estar inserido no rol de direitos fundamentais brasileiros. Portanto, se a morte faz parte da vida e, por conseguinte, o direito à vida pressupõe viver dignamente, tem-se que tal direito não se resume ao nascer, não se admitindo assim morrer sem dignidade.

No Brasil, a doutrina, o Conselho Federal de Medicina e até o Poder Judiciário associam diretamente o direito fundamental à morte digna com a ortotanásia, sendo classificada como a morte certa aquela que não prolonga a vida nem antecipa a morte. Assim, o direito de escolha do brasileiro é restrito ao acesso aos cuidados paliativos quando não se é possível ter a cura como opção (23).

Há, no Brasil, uma compreensão social e jurídica de que não cabe ao indivíduo abrir mão de sua própria vida, abreviando a morte, mesmo que ele esteja com uma doença terminal. A inviolabilidade do direito à vida, preceito constitucional, é usada como argumento para retirar a autonomia da pessoa no que diz respeito à sua morte. Mas olvida-se de que a dignidade da pessoa humana é fundamento da Constituição Federal brasileira. Assim, a vida constitucionalmente protegida é a vida digna, cabendo exclusivamente ao indivíduo a conformação do que seja digno para si.

Nesse sentido, deve-se questionar se a vida constitucionalizada - é tratada no Brasil como um direito ou um dever, pois, como não há possibilidade de o cidadão brasileiro decidir individualmente qual é o seu conceito de morte digna, acaba-se por reduzir a dignidade no morrer ao acesso aos cuidados paliativos.

Verifica-se, portanto, a impossibilidade de se afirmar que o Brasil reconheça o direito à morte digna, por limitar o direito de escolha e por definir anteriormente o que seria dignidade ao morrer. Em um ambiente reconhecidamente pluralista, negar a quem reclame o direito de morrer, quando a vida em si não passar de tortura, e defender que os cuidados paliativos serão a resposta para toda questão atinente à finitude humana é ceder à tirania.

O que se afere é que há uma prevalência da vida biológica sobre a vida biográfica do indivíduo, sobretudo quando se coloca os cuidados paliativos como antagônicos à morte medicamente assistida. Portanto, ao se falar em preservação da autonomia, é preciso verificar se está sendo resguardada a vontade conveniente do Estado ou do profissional de saúde ou a legítima liberdade decisória do paciente. 


\section{Morte medicamente assistida}

O valor da vida vai além de seus aspectos biológicos, compreendendo seu aspecto biográfico e, por conseguinte, sua plenitude e dignidade. Sobre isso, Günter Jakobs enuncia que "o valor principal não é a vida como fenômeno biológico, senão sua qualidade ou, ao menos, sua suportabilidade, já que, como qualquer um pode julgar em qualquer momento, viver não significa preocupar-se continuamente pela saúde" $(24$, p. 35$)$.

Dessa forma, tem-se que, no texto constitucional, a vida se trata de um direito, percepção que é obtida tão logo que se lê o caput de seu artigo $5^{\circ}$, que enuncia a "inviolabilidade do direito à vida." A respeito disso, Emerson Ike Coan enuncia que, por ser classificada com um direito fundamental, a vida é um direito irrenunciável, mais do que isso, se consubstancia em um direito indisponível, tendo em vista que "o homem não vive apenas para si, mas para cumprir missão própria na sociedade, assim, absoluto, fundamental" (25, p. 259).

Entretanto, a classificação da vida como um valor irrenunciável, acaba por torná-la um dever e não um direito. Consoante a isso, Piovesan e Dias elucidam (26, p. 66):

A vida não deve ser entendida como um dever para consigo mesmo, mas como um direito a algo, composto por três elementos: o sujeito do direito, ou seja, aquele que está vivo; os responsáveis pela obrigação correspondente ao direito, que são todos os que têm o dever de respeitar e preservar o direito, ativa e passivamente; e o objeto do direito, isto é, o valor protegido, qual seja a própria vida.

Destarte, faz-se necessário que esses três elementos sejam analisados conjuntamente em cada caso, sendo um erro considerar a vida como um dever universal; assim, quanto ao seu caráter inviolável, tem-se que não remete à obrigatoriedade ou a um caráter absoluto. $\mathrm{O}$ que a Constituição Federal pretende resguardar é que ninguém seja privado da vida de forma arbitrária; portanto, trata-se de um imperativo relacionado diretamente a terceiros, que estão proibidos de atentar contra a vida alheia (26).
Verifica-se, assim, que o texto constitucional não veda o titular do bem jurídico da vida o direito de decidir sobre, de acordo com suas crenças, tampouco afirma que se trata de um direito irrenunciável. Sobre isso, Jorge Reis Novais aclara (27, p. 287):

a renúncia é também uma forma de exercício do direito fundamental, dado que, por um lado, a realização de um direito fundamental inclui, em alguma medida, a possibilidade de se dispor dele, inclusive no sentido da sua limitação, desde que esta seja uma expressão genuína do direito de autodeterminação e livre desenvolvimento da personalidade individual.

Virgílio Afonso da Silva afirma que os direitos fundamentais não apresentam caráter de irrenunciabilidade, tendo em vista que todos eles admitem ponderação. Assim, não importa de qual direito fundamental se está falando, vez ou outra se acabará por colidir e será necessário estabelecer entre eles o que se chama "relação de precedência condicionada”. Tal relação pressupõe analisar de acordo com o caso concreto qual direito precede o outro, isto é, que seja realizado um sopesamento capaz de harmonizá-los (28).

Discutir as características inerentes ao direito à vida é importante, haja vista que um dos argumentos apresentados à oposição da morte medicamente assistida é a convicção de que a vida humana é sagrada, pelo que, por ser dada por um deus, ninguém poderia dela dispor. De acordo com isso, o sofrimento seria condição inerente à humanidade, sendo preciso tolerá-lo até que a morte natural chegue (29).

Diante disso, é imperioso discutir acerca da liberdade religiosa e do princípio da laicidade do Estado. No Brasil, tais valores são estipulados constitucionalmente, haja vista que a consagração de um Estado democrático de Direito se deu com a separação entre Estado e religião.

O princípio do Estado laico proíbe a fusão entre Estado e religião (como ocorrem nas teocracias), de modo a proteger a liberdade religiosa. Por outro, requer a atuação positiva do Estado no sentido de assegurar uma arena livre, pluralista e democrática em que toda e qualquer religião mereça igual consideração e respeito. 
A laicidade estatal demanda tanto a liberdade religiosa como a igualdade no tratamento conferido pelo Estado às mais diversas religiões. (26, p. 66)

Tal separação é necessária tendo em vista que a determinação de uma religião como oficial ao Estado implica a assunção de dogmas e a construção de uma moral única, que é contrária a um projeto de sociedade democrática e plural. Destarte, um Estado consagrado como democrático de Direito não pode assumir a voz exclusiva de qualquer religião, o que não impede que grupos religiosos tenham o direito de construir suas crenças e viver de acordo com elas, mas impede que essas crenças sejam impostas aos demais (26).

De acordo com isso, os direitos intrinsecamente ligados à dignidade da pessoa humana, à autonomia, à liberdade, à vida e à morte devem ser vivenciados em conformidade com um Estado pluralista sem a interferência de dogmas religiosos, sobretudo porque é sabido que as diferentes religiões enxergam a morte de formas diversas (30).

Entende-se que a existência de uma autonomia para morrer está diretamente relacionada à liberdade do indivíduo de efetivar seu projeto biográfico e exercer a sua pessoalidade. Nesse sentido, tem-se que em estados pluralistas "não compete ao governo ditar aquilo que seus cidadãos devem pensar sobre os valores éticos e espirituais, em especial sobre valores religiosos" (31, p. 37).

Essa construção de pensamento leva à reflexão acerca da noção de liberdade negativa, elucidada por Noberto Bobbio como a "situação na qual um sujeito tem a possibilidade de fazer ou de não fazer, sem ser obrigado a isso ou sem que o impeçam outros sujeitos" (31, p. 37). De acordo com essa noção de liberdade, defende-se que as escolhas dos indivíduos sejam legítimas desde que não ocasionem danos aos demais da sociedade.

Albert Calsamiglia lembra que o acesso ao direito à morte medicamente assistida e a sua relação com o direito constitucional da liberdade não devem interessar ao Estado, pois, caso contrário, a atitude configuraria como um paternalismo injustificado (32). Similarmente, tratar desse assunto pela ótica penalista é empurrar a prática à clandestinidade e se configura como uma forma de tirania. Nas palavras de Dworkin:
Dentre todas as decisões tomadas por alguém, as que dizem respeito à vida e à morte são as mais importantes e cruciais para a formação e expressão da personalidade; achamos crucial que sejam tomadas com acerto, mas também consideramos crucial que nós mesmos às tomemos, que estejam em consonância com nosso modo de ver as coisas. $(29$, p. 342$)$

Sabe-se, contudo, que um dos direitos mais caros à seara penalista é o direito à vida. A sua proteção, tal qual foi explicado anteriormente, engloba a noção de que ninguém pode tirar a vida de outrem arbitrariamente; para tanto, não há só punição às condutas culposas, em que o agente age com negligência, imprudência e imperícia, mas também às ações dolosas.

Entretanto, convém salientar que a intervenção penal não difere a arbitrariedade do cometimento de um homicídio doloso da manifestação autônoma do paciente em decidir que sua vida seja abreviada através da morte medicamente assistida. Desse modo, no Brasil, quando há um terceiro que, através de uma atitude comissiva, abrevia a vida de um doente incurável, terminal ou não, a seu pedido - prática tida como eutanásia - responderá pelo crime de homicídio doloso, tipificado no artigo 121 do Código Penal. A prática não é só vista como crime, mas também como ilícito ético pelas normas do Conselho Federal de Medicina.

Além disso, acrescenta-se que tramita no Congresso Federal o projeto de Lei do Senado 236/2012, que se trata do novo Código Penal. Anteriormente, em suas versões originais, a intenção era tratar a eutanásia como crime contra a vida diverso do homicídio, possibilitando que o agente fosse julgado pela conduta, mas pudesse receber perdão judicial em determinadas circunstâncias. Contudo, o tipo penal foi retirado do projeto antes mesmo que se pudesse discutir socialmente sobre o assunto (18).

Historicamente, o conceito da eutanásia e até a sua tratativa social passaram por várias alterações, tanto que Leo Pessini descreve três etapas que podem ser observadas ao longo dos anos (33). A primeira é chamada "eutanásia ritualizada", que diz respeito à civilização greco-romana, em que a prática era considerada como um ritual e significava "boa morte". A origem etimológica do termo se 
deve a essa noção, visto que o prefixo "eu" significa boa e "thanatos" corresponde à morte.

A seguir, tem-se a "eutanásia medicalizada", que é oriunda da Grécia Antiga e da medicina da época. Sua justificativa remontava à ideia hipocrática de que o foco da medicina deve ser a cura; assim, quando não era mais possível obtê-la, não havia mais o que ser feito. Eis que, no Renascimento, Francis Bacon reavive essa discussão ao defender que o médico deve adquirir habilidades para que o paciente desenganado possa morrer de forma mais silenciosa e fácil. Ideia que fez renascer a justificativa da realização da eutanásia por compaixão (33).

Porém, com o cristianismo, a prática ganhou novo significado, passando a ser considerada como um ilícito religioso, moral e legal, sendo, portanto, combatida. Da mesma forma se deu com a ressignificação do tema pelo nazismo, momento em que a eutanásia foi associada à eugenia, a fim de prevenir enfermidades hereditárias, o que também ocasionou um forte sentimento mundial de contrariedade à eutanásia (33).

Após a Segunda Guerra Mundial, com a derrocada do nazismo, iniciou-se um movimento a favor da autonomia dos pacientes, enquanto sujeitos de direitos, o que está intimamente ligado à noção de eutanásia autônoma. Nessa terceira fase, o paciente é colocado no centro, já que é ele quem deseja a morte e é quem provoca compaixão no médico (33).

Contudo, mesmo estando no século XXI sob a égide da ideia de eutanásia com valores humanísticos, a prática é lícita apenas em cinco países do mundo, a saber: Bélgica, Canadá, Colômbia, Holanda e Luxemburgo. Não obstante, a discussão sobre o tema está avivada em outros países como Espanha, Estados Unidos da América, Itália e Portugal.

Não obstante a essas considerações, há quem se refira à mistanásia como eutanásia social, como se tratasse de abordagens parecidas. Todavia, a referência é inapropriada, tendo em vista que a intenção por detrás da eutanásia é propiciar ao paciente que está sofrendo uma morte indolor, enquanto a mistanásia diz respeito à morte miserável, experimentada antes da hora por falta de acesso ao sistema de saúde. Nas palavras de Pessini e Ricci, "a mistanásia é geralmente a morte do pobre, resultado de uma vida precária e com pouca ou nenhuma qualidade" (34, p. 182).

Por vezes, a eutanásia também é confundida com o suicídio assistido. Vale esclarecer que, assim como ela, se trata de uma espécie de morte medicamente assistida, mas apresenta suas peculiaridades. O suicídio em si é uma das discussões mais antigas e polêmicas acerca da morte. Sobre isso, Maria de Fátima Freire de Sá $(35$, p. 197) elucida que:

Desde a antiguidade este tema é posto em debate como, por exemplo, na metáfora da sentinela, presente em Platão, segundo a qual a sentinela só pode deixar o seu posto quando houver uma autorização superior. Logo, se a vida não pertence ao homem, uma vez que ele não escolhe o momento de nascer, por que ele poderia deixar a vida por mera deliberação? Argumento semelhante contrário ao suicídio se vê nos textos de Aristóteles. Para ele o suicídio seria um atentado contra a cidade na qual o homem encontra-se inserido. Todo argumento aristotélico decorre da forma como o pensador compreende a relação necessária entre homem e a polis.

Acrescenta-se que o termo "suicídio" foi cunhado no século XVII, ganhando notoriedade com o livro A cidade de Deus, de Agostinho de Hipona, em que declarou que matar a si mesmo pode ser visto como uma variável do mandamento dado pelo Deus cristão "Não matarás" (36, p. 15).

Já no século XVIII, apesar de não ter uma obra especificamente sobre o suicídio, Kant foi um grande opositor do suicídio. Afirmou, assim, que, embora o homem seja livre, há que honrar os deveres para consigo mesmo, classificando assim o ato como um assassinato e, por conseguinte, um crime (37). $\mathrm{Na}$ atualidade, o suicídio é tratado como questão de saúde pública, por estar ligado às motivações clínico-psiquiátricas, gerando uma preocupação social acerca do adoecimento mental da população.

Na legislação brasileira, não há qualquer norma específica sobre o suicídio assistido, tampouco projeto de lei sobre o tema. É sabido que inexiste qualquer obrigação constitucional de viver, sendo que tirar a própria vida não é criminalizado, 
todavia aquele que preste assistência ao suicídio será responsabilizado pelo crime de induzimento, instigação ou auxílio ao suicídio, de acordo com o que dispõe o artigo 122 do Código Penal (35).

O suicídio assistido é tido como abreviação da vida realizada pela própria pessoa que está com uma doença terminal, grave e/ou incurável, pelo que é ajudada por um terceiro, que lhe concede os meios para que abrevie sua vida por si mesma (25). Tem-se que em todos os países que legalizaram a eutanásia, excetuando a Colômbia, legalizaram também o suicídio medicamente assistido.

Verifica-se ainda que há lugares em que tal modalidade é permitida (Suíça e alguns estados estadunidenses), enquanto a eutanásia continua proibida. Isso pode ser explicado pelo fato de que existe certa tolerância cultural ao suicídio assistido, uma vez que "esta é uma maneira de não envolver os profissionais de saúde no ato da eutanásia, uma vez que é a própria pessoa quem toma a decisão e realiza as medidas necessárias para garantir a sua morte" (38, p. 1743$)$.

A Academia Suíça de Artes e Ciências estabeleceu em suas diretrizes que o suicídio assistido é justificável em se tratando de pacientes capazes de julgamento que estejam vivenciando sofrimento intolerável causado por sintomas de doença e/ou deficiência funcional, que não pode ser aplacado por outras opções (39).

A legislação não estipula nenhum tipo específico de sofrimento, tampouco diagnóstico médico, mas exige, porém, que o paciente esteja diante de uma condição incurável ou terminal. Todavia, as diretrizes são diretas em elucidar que o paciente não possui direito ao suicídio assistido, sendo dada ao médico a liberdade para considerar ou não essa ação (39).

Interessante pontuar que a discussão sobre autonomia no direto de morrer está tão avançada na Suíça que, atualmente, se discute o chamado "suicídio racional", hipótese defendida pela Life Circle e pela Pegasos, organizações que lutam pelo direito à morte com dignidade. Defende-se, aqui, que idosos sem qualquer diagnóstico de doenças ameaçadoras de vida possam decidir de forma racional pelo suicídio assistido (40), por entender que o envelhecimento é em si uma condição incurável e que, a essa altura, as pessoas já tiveram vidas completas (40).

Nesse sentido, apesar de ser um conceito controverso e difícil de definir, entende-se que o suicídio racional se trata de "uma decisão sã, bem pensada e razoavelmente estável, por um indivíduo mentalmente capaz de raciocinar e escolher a melhor alternativa dentre as muitas disponíveis sem ambivalência” (41, p. 141).

A respeito disso, Gramaglia (42) afirma que o direito de morrer traz dois significados: o direito de recusar tratamento de manutenção de vida e um direito afirmativo de obter a morte - um direito ao suicídio. Todavia, há quem expresse a preocupação de que reconhecer o direito de morrer levaria ao dever social e obrigatório de morrer. A justificativa para tanto está em que a ideação suicida é em si uma manifestação de doença psiquiátrica, não sendo viável considerá-la como uma decisão dotada de racionalidade (42).

Os argumentos não param por aí, tendo em vista o alto número de suicídios entre pessoas idosas no mundo. Considerando as tendências mundiais de envelhecimento e a grande probabilidade de que, em idades avançadas, surjam doenças psiquiátricas não reconhecidas e tratadas, acende-se o alerta para não se negligenciar o suicídio em idosos (43). Desse modo, resta citar outra preocupação: o ageísmo. Apoiar a possibilidade de suicídio racional para pessoas idosas seria uma forma de dizer que o envelhecimento resulta em uma vida que não vale a pena ser vivida?

Não obstante a essas considerações, que inegavelmente devem ser avaliadas quando se está diante de uma manifestação pelo suicídio racional, alerta-se para o cuidado ao afirmar que todo pedido de suicídio é patológico ou que pessoas idosas nunca são capazes de decidir por si próprias, a fim de não incorrer em paternalismo (44). Falar em autonomia pressupõe, primeiramente, discernimento e que haja consentimento informado por meio de uma explicação completa dos riscos e dos benefícios ao paciente, para que só então ele possua agência para tomar decisões a respeito de seu tratamento.

Destarte, em países que sejam democráticos e plurais, o desafio é entender que a morte assistida 
é um ato que expressa o livre arbítrio, pelo que a centralidade do debate deve estar em garantir que a manifestação pelo direito de morrer seja livre, consciente e informada. Nesse sentido, o papel da Bioética é auxiliar que a morte digna deixe de ser um tabu na sociedade e passe a ser enfrentada como uma questão de direitos humanos.

\section{Interrupção voluntária de comer e beber}

A expressão "morte digna" deve ser entendida como a possibilidade de o paciente decidir como deseja morrer, tendo em vista que já está diante de uma condição incurável e irreversível. Para tanto, primordialmente, faz-se necessário que haja acesso aos cuidados paliativos, pressuposto de dignidade. Entende-se que essa abordagem é altamente eficaz quando fornecida por uma equipe multidisciplinar e qualificada, capaz de dar atenção às necessidades físicas, psicológicas, sociais e espirituais dos pacientes e de suas famílias.

No entanto, apesar dos esforços da abordagem paliativa, é possível que os sofrimentos persistam ou se agravem, razão pela qual alguns pacientes se manifestam pela antecipação da morte. É possível também que, mesmo estando bem paliado, o paciente veja razões para pedir eutanásia ou assistência ao suicídio (45).

Débora Diniz (38, p. 1 743) esclarece que " não apenas médica, mas também ética e jurídica." Contrariamente, no Brasil, não é dado ao paciente idoso ou em situação de terminalidade de vida a opção pela eutanásia e pelo suicídio assistido, tampouco a possibilidade de interrupção voluntária da hidratação e da nutrição em fim de vida.

Tal medida é conceituada como uma ação tomada por uma pessoa capaz, que, no intuito de findar um sofrimento inaceitável, decide parar de comer e beber a fim de acelerar a morte. Tem-se que é uma prática relacionada aos pacientes que não apresentam comprometimento cognitivo $\mathrm{e}$ que são fisicamente capazes de ingerir alimentos e líquidos por via oral, mas que, de forma consciente, decidem não o fazer (46).

Por isso, é importante distinguir essa prática de outros motivos que levam a interromper a hidratação e a nutrição pela via oral, como a incapacidade de comer e beber, o desinteresse por alimentos e bebidas e a perda de apetite, sintomas comuns em fase de terminalidade de vida (46).

A prática tem por sinônimos as expressões "recusa/parada voluntária de alimentos e líquidos" ou "recusa/parada de hidratação e nutrição dos pacientes" (47). É entendida como morte natural (48), cuja decisão é reversível nos primeiros dias, sendo um meio capaz de acelerar a morte e uma alternativa ao suicídio assistido e à eutanásia do ponto de vista ético, tendo em vista que não é um procedimento ordenado por médico ou por ele dirigido (49).

Os relatos de casos propostos tendem a apresentar uma análise positiva da interrupção de comer e beber em casos de fim de vida, por ser capaz de fornecer alívio ao sofrimento, ao mesmo tempo em que denota controle e autonomia. Além disso, em razão de a morte não ocorrer de forma rápida, tal qual a morte medicamente assistida, permite ao paciente tempo para reconsiderar a decisão e, ao ambiente social, que se prepare mentalmente para o momento conclusivo, assim como dá o tempo necessário para que erros de comunicação ou mal-entendidos no processo da tomada de decisão sejam resolvidos (46).

No que tange ao perfil de pacientes que solicitam a medida, estudos demonstram que apenas uma pequena parcela teria optado pelo suicídio assistido ou pela eutanásia caso fossem opções disponíveis. Porém, entre as motivações para se acelerar o processo de morrer, percebe-se que vários motivos os unem, por exemplo, ter uma opção quando as medidas paliativas são ineficazes, sendo que o procedimento é solicitado, em sua maioria, por pacientes com doenças terminais irreversíveis (50).

Além disso, afere-se que, na grande parte dos casos, em razão da deterioração da saúde, o ônus de se manter a vida superava os benefícios segundo os pacientes, pelo que a prontidão em morrer, a má qualidade de vida, o sentimento de ser um fardo à família e a necessidade de recuperarem sua autonomia se mostraram as razões mais recorrentes (46). 
Não é possível precisar em quantos dias a morte é acelerada, uma vez que o resultado dependerá da situação clínica e dos termos do próprio paciente; contudo, a literatura menciona com mais frequência entre uma e três semanas do início do jejum (51).

Schwarz (51) aponta que o desejo de morte apressada ocorre regularmente, mas esses pensamentos são frequentemente mantidos em segredo pelos pacientes, a menos que os médicos indiquem especificamente. Pesquisas demonstram que os pacientes que optam por acelerar a morte através da interrupção voluntária da hidratação e da nutrição, por vezes, não envolvem os profissionais de saúde que os acompanham nessa decisão, por receio de não serem compreendidos e que serem dissuadidos da ideia (46).

Essa ocorrência leva à preocupação de que os pacientes não recebam os cuidados devidos, desde o aconselhamento e o fornecimento de informações necessárias sobre a medida, ao gerenciamento e ao suporte de sintomas ao longo de sua execução (46), mas deve-se ter em mente que, apesar da natureza autônoma existente nessa prática, o apoio médico e o fornecimento de cuidados paliativos se mostram essenciais (52).

Do ponto de vista dos profissionais de saúde, a interrupção voluntária de comer e beber deve ser fornecida como último recurso, e a ausência de cuidados paliativos não pode embasar esse pedido. Recomenda-se que, antes de executá-la, seja obtido o consentimento informado do paciente, assim como haja uma avaliação de sua capacidade em compreender o tratamento e as demais alternativas (53).

Acrescenta-se que a literatura demonstra a importância de se obter a segunda opinião de um especialista em cuidados paliativos, em saúde mental ou de um especialista na doença subjacente do sujeito, a fim de aferir se sua decisão está sendo afetada por depressão ou outros transtornos psicológicos. Recomenda-se também que a família seja envolvida nesse processo, assim como os profissionais de saúde que compõem a equipe para evitar conflitos morais. Sobre isso, ressalta-se a importância do consentimento da equipe médica, vez que, existindo opiniões contrárias à decisão do paciente, será necessário encaminhá-lo a outros profissionais (46).

Por fim, é imprescindível que todo o procedimento seja documentado de forma detalhada, para fins de responsabilização, sendo recomendável que o procedimento seja realizado sob monitoramento e apoio de profissionais dos cuidados paliativos, haja vista que parar de comer pode ocasionar outros sintomas que requerem cuidados. Contudo, as pesquisas acerca das intervenções de suporte, como a sedação terminal, são discutidas de forma controversa, pelo que não há certeza quanto aos seus benefícios (54).

Aliás, é essencial esclarecer que, apesar de a interrupção voluntária de comer e beber já ser discutida há mais de 20 anos, não há produções científicas extensas sobre o assunto (46). Percebe-se que se trata de um tópico que fica à margem nas discussões de morte digna. Algumas possíveis razões podem ser apontadas, a saber: a suposição existente no meio da saúde de que a prática ocasiona mais sofrimento e tensão ao paciente, assim como a crença de que é antiético permitir que um paciente deliberadamente acelere a morte (55); a interpretação pelos membros da família de que se trata de uma forma de negação, assim como o alto valor social que é dado à ingestão de alimentos (56).

Consoante a isso, Correia e Maurício (57, p. 98) explicam

Nos cuidados do fim da vida, a alimentação e hidratação ainda são assuntos conflitantes que envolvem contradições, mitos e emoções. [...] Decidir sobre alimentação e hidratação nesse momento é complicado, pois são temas polemizados há décadas e os benefícios permanecem questionados.

Assim, é preciso diferenciar a (i) interrupção voluntária da hidratação e da nutrição como alternativa para se abreviar a vida da (ii) interrupção, suspensão ou não administração de hidratação ou alimentação no contexto de doenças ou estados terminais e/ou irreversíveis, ocasião em que tais recursos não proporcionam mais benefícios ao paciente.

A interrupção voluntária da hidratação e da nutrição usada como alternativa para se abreviar 
a vida e depender de auxílio de terceiro pode ser encarada como ilícita no Brasil, sob a perspectiva penal, pois o artigo 122 do Código Penal pune o auxílio e o induzimento ao suicídio (art. 122 do Código Penal). Todavia, se a pessoa deliberadamente

parar de se hidratar e de se alimentar, não é lícito que o profissional de saúde imponha a nutrição e a hidratação, sob pena de violar o direito constitucional à autonomia, o direito existencial à recusa de tratamento (art. 15 do Código Civil) e praticar o crime de lesão corporal (art. 129 do Código Penal).

Vale acrescentar que o tema é pouco explorado no mundo, tanto na perspectiva bioética quanto na perspectiva jurídica, inexistindo produção científica, o que pode ser justificado pelo fato de que predomina, nos ambientes de saúde, a abordagem curativa, além da proibição legal de métodos mais abrangentes à autonomia de morrer.

\section{Conclusões}

Desse modo, conclui-se que a interrupção voluntária de comer e beber se trata de um tema envolto de tabus e que, por conseguinte, precisa ser mais discutido. Sua abordagem no ordenamento jurídico brasileiro deve vir acompanhada de discussões responsáveis sobre a autonomia do paciente ante a morte medicamente assistida. Todavia, a inexistência de lei específica não é razão para considerar a prática ilícita, vez que há substrato constitucional, civil e penal para fundamentá-la.

Embora agora seja preciso avançar no que tange ao direito ao acesso universal aos cuidados paliativos, não é possível restringir o direito de morrer à ortotanásia. Assim, é fundamental avançar também na discussão sobre o processo de morrer, haja vista que considerá-lo como fundamental ao processo de construção de pessoalidade implica enxergá-lo não como afronta ao direito à vida, mas como a efetivação de um projeto de vida digna.

É cediço que há muitos percalços culturais, sociais e religiosos no Brasil quando se trata da interrupção voluntária da hidratação e da nutrição, mesmo em fim de vida, por isso o debate bioético e jurídico, sob a perspectiva do direito à autodeterminação, se faz tão importante. Sobretudo quando se reconhece que pela perspectiva constitucional, a morte digna é assegurada como um direito implícito, decorrente da dignidade da pessoa humana e do pluralismo.

\section{Referências}

1. Gawande A. Mortais. Nós, a medicina e o que realmente importa no final. Rio de Janeiro: $\mathrm{Ob}$ jetiva; 2015.

2. Pessini L. Vida e morte na UTI: a ética no fio da navalha. Revista Bioética [internet]. 2016 [acesso em 20 de jun. de 2020];24(1):54-63. Dor: http:// dx.doi.org/10.1590/1983-80422016241106

3. Kaiser Foundation. Views and experiences with end-of-life medical care in Japan, Italy, the United States, and Brazil: A cross-country survey (internet) [acesso em 25 jun. 2020]. Disponível em: https://www.kff.org/other/report/ views-and-experiences-with-end-of-life-medical-care-in-japan-italy-the-united-states-and-brazil-a-cross-country-survey/

4. Drane James F. El cuidado del enfermo terminal: ética clínica y recomendaciones prácticas para instituciones de salud y servicios de cuidados domiciliarios. Washington: Organización Panamericana de la Salud; 1999.

5. American Medical Association. Medically ineffective interventions: Code of medical ethics opinion 5.5 (internet). Chicago; 2019 [acesso em 27 jun. 2020]. Disponível em: https://www.ama-assn.org/delivering-care/ medically-ineffective-interventions

6. Pessini L. Distanásia: até quando prolongar a vida? São Paulo: Loyola; 2001.

7. Brito A, Rijo J. Estudo jurídico da eutanásia em Portugal: direito sobre a vida ou dever de viver. Coimbra: Almedina; 2000.

8. Beauchamp T, Childress JF. Princípios de ética biomédica. Trad. Luciana Pudenzi. São Paulo: Loyola; 2002.

9. Garay OE. Derechos fundamentales de los pacientes. Buenos Aires: Ad-Hoc; 2003.

10. Post SG. Encyclopedia of bioethics. $3^{\mathrm{a}}$ ed, v. 3. Nova York: Thomson; 2004.

11. Dalal S, Palla S, Hui D, Nguyen L, Chacko R, 
Li $\mathrm{Z}$ et al. Association between a name change from palliative to supportive care and the timing of patient referrals at a comprehensive cancer center. The Oncologist (internet). 2011[acesso 20 jun. 2020];16:105-11. DoI: 10.1634/theoncologist.2010-0161

12. Pessini L. A filosofia dos cuidados paliativos: uma resposta diante da obstinação terapêutica. In: Pessini L, Bertachini L, orgs. Humanização e cuidados paliativos. $3^{\mathrm{a}}$ ed. São Paulo: Loyola; 2006. p. 195.

13. Mccoughlan M. A necessidade de cuidados paliativos. In: Pessini L, Bertachini L, orgs. Humanização e cuidados paliativos. $3^{\text {a }}$ ed. São Paulo: Loyola; 2006. p. 168.

14. Sepúlveda C, Marlin A, Yoshida T, Ullrich A. Palliative care: the World Health Organization's global perspective. Journal of Pain and Sympton Management [internet]. 2002 [acesso em 25 de jun. de 2020], ;24(2):92. Dor: https:// doi.org/10.1016/S0885-3924(02)00440-2

15. International Association for Hospice and Palliative Care (IAHPC). Palliative care definition [internet]. Houston; 2019 [acesso em 26 jun. 2020]. Disponível em: <https:// hospicecare.com/what-we-do/projects/consensus-based-definition-of-palliative-care/ definition/>

16. Burla C. Cuidados paliativos: ciência e proteção ao fim da vida. Caderno de Saúde Pública. 2014 [acesso em 2 ago. 2020];30(6):1139-41. DoI: https://doi.org/10.1590/0102-311XPE020614

17. Taboada $\mathrm{P}$. El derecho a morir com dignidade. Acta Bioethica [internet]. 2000 [acesso em 3 ago. 2020];6(1):89-101. DoI http://dx.doi. org/10.4067/S1726-569X2000000100007

18. Dadalto L. Testamento vital. $5^{\text {a }}$ ed. Indaiatuba: Foco; 2019.

19. Godinho AM. Ortotanásia e cuidados paliativos: o correto exercício da prática médica no fim da vida. In: Dadalto L, Godinho AM, Leite GS, orgs. Tratado brasileiro sobre o Direito Fundamental à morte digna. Rio de Janeiro: Almedina; 2017. P. 131-150.
20. Villas-Bôas ME. Da eutanásia ao prolongamento artificial: aspectos polêmicos na disciplina jurídico-penal do final de vida. Rio de Janeiro: Forense; 2005.

21. Villas-Bôas ME. Eutanásia passiva e ortotanásia: uma distinção necessária. In: Dadalto L, org. Bioética e diretivas antecipadas de vontade. Curitiba: Editora Prismas; 2014.

22. Lêdo APR, Sabo IC, Amaral ACZM. Existencialidade humana: o negócio jurídico na visão pós-moderna. Civilistica [internet]. 2017 [acesso em 27 jun. 2020];6(1): 1-22. Disponível em: <http://civilistica.com/ existencialidade-humana-o-negocio-juridico/>

23. Dadalto L. Morte digna para quem? O direito fundamental de escolha do próprio fim. Revista de Ciências Jurídicas [internet]. 2019 [acesso em 3 ago. 2020]; 24(3):1-11. DOI: 10.5020/2317-2150.2019.9555

24. Jakobs G. Suicídio, eutanásia e direito penal. São Paulo: Manole; 2003.

25. Coan EI. Biomedicina e biodireito. Desafios bioéticos. Traços semióticos para uma hermenêutica constitucional fundamentada nos princípios da dignidade da pessoa humana e da inviolabilidade do direito à vida. In: Santos MCCL, org. Biodireito: ciência da vida, os novos desafios. São Paulo: Editora RT; 2001, p.259.

26. Dias R, Piovesan F. Proteção jurídica da pessoa humana e o direito à morte digna. In: Dadalto L, Godinho AM, Leite, GS. Tratado brasileiro sobre o Direito Fundamental à morte digna. São Paulo: Almedina; 2017, orgs. P. 66.

27. Novais JR. Direitos fundamentais: trunfos contra a maioria. Coimbra: Coimbra Editora; 2006.

28. Silva VA. A constitucionalização do direito: os direitos fundamentais nas relações entre particulares. São Paulo: Malheiros Editora; 2014.

29. Dworkin R. Domínio da vida: aborto, eutanásia e liberdades individuais. São Paulo: WMF Martins Fontes; 2009.

30. Pessini L. A eutanásia na visão das grandes religiões mundiais. Revista Bioética [internet]. 2009 [acesso em 30 jun. 2020];7(1):1-2. 
Disponível em: https://revistabioetica.cfm.org. br/index.php/revista_bioetica/article/view/296.

31. Bobbio N. Iguladad y libertad. Barcelona: Grupo Planeta; 1993, org..

32. Calsamiglia AB. "Sobre la eutanásia". In: Vásquez R. Bioética y derecho: fundamentos y problemas actuales. $2^{\mathrm{a}}$ ed. México: Fondo de Cultura Económica e Instituto Tecnológico Autónomo de México; 2002.p. 151-175.

33. Pessini L. Eutanásia: por que abreviar a vida? São Paulo: Loyola; 2004.

34. Pessini L, Ricci LAL. O que entender por mistanásia? In: Dadalto L, Godinho AM, Leite GS, orgs. Tratado brasileiro sobre o Direito Fundamental à morte digna. São Paulo: Almedina; 2017. P. 182.

35. Sá MFF, Moureira DL. Suicídio assistido. In: Dadalto L, Godinho AM, Leite GS, orgs. Tratado brasileiro sobre o Direito Fundamental à morte digna. São Paulo: Almedina; 2017, p. 197.

36. Puente, FR. Os filósofos e o suicídio. Belo Horizonte: UFMG; 2008.

37. Kant I. A metafísica dos costumes. Trad. por Edson Bini. Bauru: Edipro; 2003.

38. Diniz D. Quando a morte é um ato de cuidado: obstinação terapêutica em crianças. Caderno de Saúde Pública [internet]. 2006 [acesso em 3 ago. 2020]; 22(8):1743. Dor: https://doi. org/10.1590/S0102-311X2006000800023

39. American Medical Association. Medically ineffective interventions: Physicians should only recommend and provide interventions that are medically appropriate [internet]. Chicago; 2019 [acesso em 1 ago. 2020]. Disponível em: https://www.ama-assn.org/delivering-care/ medically-ineffective-interventions

40. Exit International. Prof David Goodall Exit International Press Conference Basel CH - Wed 3pm. [internet]. Austrália; 2018. (acesso em 1 ago. 2020). Disponível em: https://exitinternational.net/exit-press-conference-basel-chwednesday-3pm/

41. Amery J. On aging: Revolt and Resignation. Bloomington: Indiana University Press; 1994.
42. Gramaglia C, Calati R, Zeppegno P. Rational suicide in late life: A systematic review of the literature. Medicina [internet]. 2019 [acesso em 2 ago. 2020];55(10):1-23. Dor: https://doi. org $/ 10.3390 /$ medicina 55100656

43. Walter M, Weber WM. Cliff, not a slope: A response to margaret pbattin. Centre for Suicide Prevention [internet].1998 [acesso em 2 ago. 2020]; 194-6. DoI: https://doi.org/10.1111/ j.1943-278X.1988.tb00154.x

44. Santos LF. A morte assistida e outras questões de fim-de-vida. Coimbra: Almedina; 2015.

45. Ivanović N, Büche D, Fringer A. Voluntary stopping of eating and drinking at the end of life: A "systematic search and review" giving insight into an option of hastening death in capacitated adults at the end of life. BMC palliative care [internet]. 2014 [acesso em 2 ago. 2020];13(1):18. DoI: https://doi.org/10.1186/1472-684X-13-1

46. Chabot BE, Goedhart A. A survey of self-directed dying attended by proxies in the Dutch population. Social Science e Medicine [internet]. 2009 [acesso em 2 ago. 2020];68(10):1745-51. DOI: https://doi.org/10.1016/j.socscimed.2009.03.005

47. Klein RU, Fringer A. Freiwilliger Verzicht auf Nahrung und Flüssigkeit in der Palliative Care: ein Mapping Review [Voluntary Refusal of Food and Fluid in palliative care: a mapping literature review]. Pflege [internet]. 2013 [acesso em 3 ago. 2020]; 26(6):411-20. DoI: https://doi. org/10.1024/1012-5302/a000329

48. Jansen LA. No safe harbor: the principle of complicity and the practice of voluntary stopping of eating and drinking. The Journal of Medicine and Philosophy [internet]. 2004 [acesso 4 ago. 2020];29(1):61-74. DoI: https://doi.org/10.1076/ jmep.29.1.61.30413.

49. Quill TE, Byock IR. Responding to intractable terminal suffering: The role of terminal sedation and voluntary refusal of food and fluids. ACP-ASIM End-of-Life Care Consensus Panel. American College of Physicians. American Society of Internal Medicine [internet]. 2000 [acesso em 10 ago. 2020];132(5):408-14. 
DoI: https://doi.org/10.7326/0003-4819-132-5200003070-00012

50. SchwarzJK. Stopping eating and drinking. America Journal of Nursing [internet]. 2009 [acesso em 10 ago. 2020];109(9):52-62. Dor: https://doi. org/10.1097/01.NAJ.0000360314.69620.43

51. Schwarz JK. Death by voluntary dehydration: Suicide or the right to refuse a life-prolonging measure? Widener Law Rev. 2011;17:351-61.

52. Christenson, J. An ethical discussion on voluntarily stopping eating and drinking by proxy decision maker or by advance directive. Journal of Hospice Palliative e Nursing [internet]. 2019 [acesso em 29 set. 2020];21(3):188-92. DOI: https://doi.org/10.1097/ NJH.0000000000000557

53. Trowse P. Voluntary stopping of eating and drinking in advance directives for adults with late-stage dementia. Australasian Journal on ageing [internet]. 2019 [acesso em 29 set. 2020];39(2):1-6. DOI: https://doi.org/10.1111/ ajag.12737

54. Rady MY, Verheijde JL. Distress from voluntary refusal of food and fluids to hasten death: what is the role of continuous deep sedation? J
Med Ethics [internet]. 2012 [acesso em 10 ago. 2020];38(8):510-2. DoI: https://doi.org/10.1136/ medethics-2011-100278.

55. Lowers J, Hughes S, Preston N. Overview of voluntarily stopping eating and drinking to hasten death. Annals of Palliative Medicine [internet]. 2020 [acesso em 13 out. 2020];1-6. DOI: https://doi.org/10.21037/apm-19-525

56. Ganzini L, Goy ER, Miller LL, Harvath TA, Jackson A, Delorit MA. Nurses' Experiences with hospice patients who refuse food and fluids to hasten death. N Engl J Med [internet]. 2003 [acesso em 10 ago. 2020]; 349:359-65. Dor: https://doi.org/10.1056/NEJMsa035086

57. Correia MI, Davidsson T, Mauricio SF. Suspensão de nutrição e hidratação em Cuidados paliativos. In: Dadalto L, coord. Bioética e diretivas antecipadas de vontade. Curitiba: Prismas; 2014. p. 98. 